Available online at http://jurnal.stmikroyal.ac.id/index.php/jurteksi

\title{
ANALISIS DENGAN METODE KLASIFIKASI MENGGUNAKAN DECISSION TREE UNTUK MEMPREDIKSI PENENTUAN RESIKO KREDIT BANK
}

\author{
Afdhal Syafnur \\ Sistem Informasi, STMIK Royal \\ email: afdhal23@gmail.com
}

\begin{abstract}
There are several facilities in distributing funds to the customer which is owned by Bank Syariah Bukopin. One of them is Kredit Pemilikan Rumah / Housing Loan (mortgage), so far the bank when provides mortgages to customers still uses risk prediction manually in giving credit to customers which is taking up a lot of time and energy especially when the customer reports is further analyzed by the Bank. One technique that can help in predicting the Bank's credit risk determination is Decision Tree which is a technique that is a part of Data Mining techniques to take a decision in the form of a tree. With Decision Tree techniques, it is expected to help the bank to allow faster and easier in predicting the data and getting a conclusion from existing data. One of the ways to predict the data is using Dtreg software. This software only uses data that is in the format of "csv (comma delimited)", if it is not using the format" csv (comma delimited)", so that the data can not be processed by Dtreg software. When the excel format has been converted to the "csv (comma delimited)" format, the analysis process can be done. Dtreg can generate decision tree, one of them is the result of risk decision from the number of mortgages based on the number of customers.
\end{abstract}

Keywords: data mining, decision tree

\begin{abstract}
Abstrak: Ada beberapa fasilitas dalam penyaluran dana ke nasabah yang di miliki Bank Syariah Bukopin. Salah satunya Kredit Pemilikan Rumah (KPR), selama ini pihak Bank memberikan KPR ke nasabah masih menggunakan prediksi resiko secara manual dalam meberikan kredit kepada nasabah yang banyak menyita waktu dan tenaga apalagi pada saat laporan nasabah dianalisa lebih lanjut oleh pihak Bank. Salah satu teknik yang dapat membantu pihak Bank dalam memprediksi Penentuan resiko kredit adalah teknik Decision Tree yang merupakan bagian dari teknik Data Mining untuk mengambil suatu keputusan dalam bentuk pohon. Dengan teknik Decision Tree diharapkan dapat membantu pihak bank agar lebih cepat dan mudah dalam memprediksi data dan menarik suatu kesimpulan dari data yang ada.Salah satu cara memprediksi data tersebut dengan menggunakan software Dtreg. Pada software ini data yang digunakan hanya bisa dalam bentuk format "csv (comma delimited), jika tidak menggunakan format "csv (comma delimited " " maka data tersebut tidak bisa diproses oleh software Dtreg dan selanjutnya jika format excel yang telah dirubah ke format "csv (comma delimited)", maka akan dapat dilakukan proses analisa. Dtreg dapat menghasilkan pohon keputusan, salah satu nya yaitu hasil keputusan resiko dari jumlah kredit pemilikan rumah berdasarkan jumlah nasabah.
\end{abstract}

Kata kunci: data mining, decision tree 
Available online at http://jurnal.stmikroyal.ac.id/index.php/jurteksi

\section{PENDAHULUAN}

Seiring dengan berkembangnya dunia teknologi informasi, kebutuhan masyarakat akan data dan informasi semakin meningkat. Data dulunya hanyalah suatu data yang tertumpuk dan tidak diolah lebih lanjut. Namun, saat ini data umumnya telah diolah sehingga dapat menghasilkan informasi. Untuk mengolah data menjadi informasi dibutuhkan suatu sistem yang terkomputerisasi dengan menggunakan database. Saat ini sistem komputerisasi tidak hanya terbatas pada perusahaan bisnis, namun juga sampai pada perusahaan yang bergerak di bidang perbankan. Salah satu fungsi dari informasi hasil pengolahan data bagi perusahaan yang bergerak di bidang perbankan (dalam hal ini pada bank Syariah Bukopin) adalah dapat menghasilkan informasi yang bersifat klasifikasi yang terkait dengan perkreditan rumah. Untuk mendapatkan informasi tersebut dapat digunakan salah satu metode Klasifikasi yang ada di data mining.

Penelitian untuk pemetaan alternatif pemecahan masalah tentang resiko kredit yang ada pada bank Syariah Bukopin didaerah Lubuk Begalung Padang dengan menggunakan aplikasi data mining yang telah ada (DTREG) agar data nasabah dapat diolah lebih lanjut dan menghasilkan informasi yang berguna untuk pengambilan keputusan oleh pihak Bank.

Teori pengambilan keputusan adalah teknik pendekatan yang digunakan dalam proses pengambilan keputusan atau proses memilih tindakan sebagai cara pemecahan masalah. Fungsi pengambilan keputusan adalah individual atau kelompok baik secara institusional ataupun organisasional, sifatnya futuristik. Secara konsep Decision tree adalah salah satu dari teknik decision analysis. Tries sendiri pertama kali diperkenalkan pada tahun 1960-an oleh Fredkin. Trie atau digital tree berasal dari kata retrival (pengambilan kembali) sesuai dengan fungsinya. Secara etimologi kata ini diucapkan sebagai 'tree'. Meskipun mirip dengan penggunaan kata 'try' tetapi hal ini bertujuan untuk membedakannya dari general tree. Dalam ilmu komputer, trie, atau prefix tree adalah sebuah struktur data dengan representasi ordered tree yang digunakan untuk menyimpan associative array yang berupa string. Berbeda dengan binary search tree (BST) yang tidak ada node di tree yang menyimpan elemen yang berhubungan dengan node sebelumnya dan, posisi setiap elemen di tree sangat menentukan. Semua keturunan dari suatu node mempunyai prefix string yang mengandung elemen dari node itu, dengan root merupakan string kosong. Values biasanya tidak terkandung di setiap node, hanya di daun dan beberapa node di tengah yang cocok dengan elemen tertentu.

\section{METODOLOGI}

Prosedur untuk melakukan analisis pohon keputusan:

1. Membuat diagram pohon (Tree Diagraming)

a. Identifikasi semua titik keputusan dan kemungkinan lain yang akan terjadi.

b. Identifikasi alternative keputusan untuk setiap titik keputusan.

c. Identifikasi apa yang mungkin terjadi dari setiap keputusan yang diambil.

d. Membuat sebuah diagram pohon yang menunjukkan urutan keputusan dan kejadian yang mungkin terjadi.

2. Estimasi kemungkinan (Expected cost $=\mathrm{EC}$ )

a. Estimasi kemungkinan hasil yang akan diperoleh dari berbagai kejadian yang mungkin terjadi.

b. Estimasi konsekuensi keuangan 


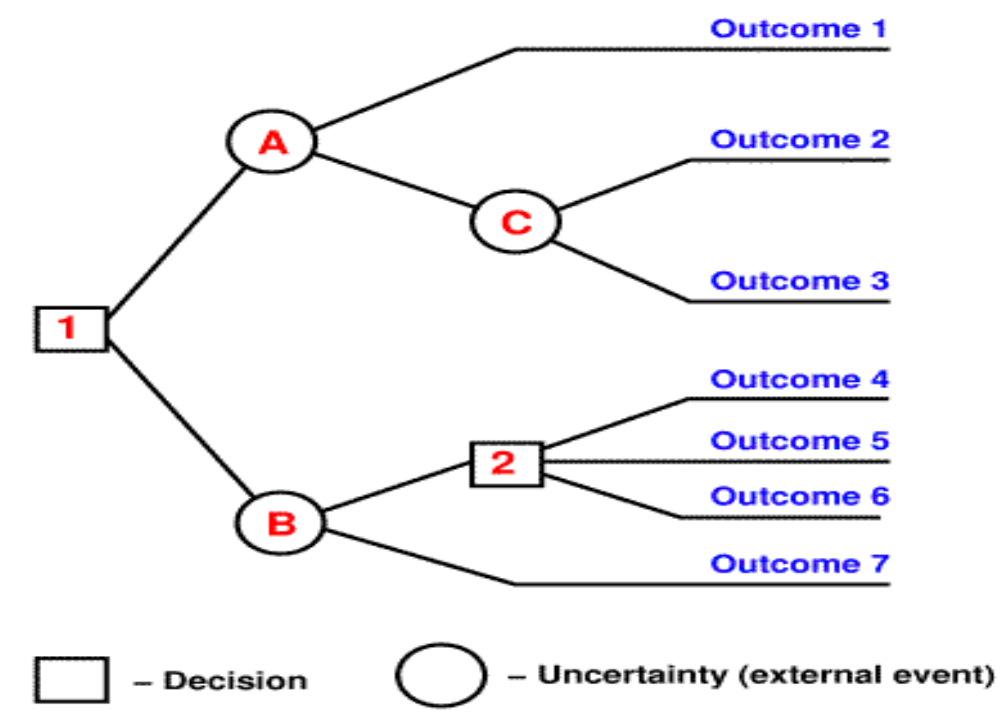

Gambar 1. Permulaan Diagram Pohon Keputusan

c. dari setiap hasil yang mungkin dari berbagai alternatif keputusan.

3. Evaluasi dan seleksi

a. Perhitungkan nilai yang diharapkan dari setiap alternatif keputusan.

b. Pilih alternatif keputusan yang menawarkan nilai yang diharapkan yang paling optimal.

Dtreg adalah analisis program statistik yang kuat yang menghasilkan klasifikasi dan pohon keputusan bahwa model regresi data dan dapat digunakan untuk memprediksi nilai. Single-pohon, pohon Tree Boots dan Model Keputusan dapat dibuat. DTREG adalah alat yang ideal untuk bisnis pemodelan, perbankan, dan medis data dengan variabel kategori seperti jumlah nasabah, jangka waktu, jaminan, resiko kredit, dan solusi yang dapat diambil. Pohon Keputusan ini logis, model yang jelas yang dapat dimengerti dengan mudah oleh orang-orang yang tidak cenderung matematis.

\section{HASIL DAN PEMBAHASAN}

Untuk memperoleh data atau informasi dalam studi kasus, tentu perlu dilakukan kegiatan pengumpulan data yang berguna sebagai penunjang. Teknik pengumpulan data terdiri dari:

a. Berdasarkan sumber data: (Sum-ber Primer: Sumber yang lang-sung memberikan data dan Sumber Sekunder: Sumber yang tidak langsung memberikan data).

b. Berdasarkan Teknik Pengum-pulan Data dibagi lagi menjadi: Observasi, Wawancara.

Adapun proses pengambilan keputusan sebagai berikut:

1. Data yang telah didapat, dalam hal ini penulis mengambil data di Bank Syariah Bukopin Lubuk Begalung Padang dimana penulis mengambil sampel datanya selama lebih krang dua bulan yaitu pada bulan Maret dan April 2011, data tersebut diketik ulang semuanya dengan menggunakan Microsoft excel dan Microsot Word karena dari pihak Bank tidak memberikan data soft copy tetapi dalam bentuk hard copy dan wawancara.Contohnya dapat dilihat pada gambar dibawah ini: 
Available online at http://jurnal.stmikroyal.ac.id/index.php/jurteksi

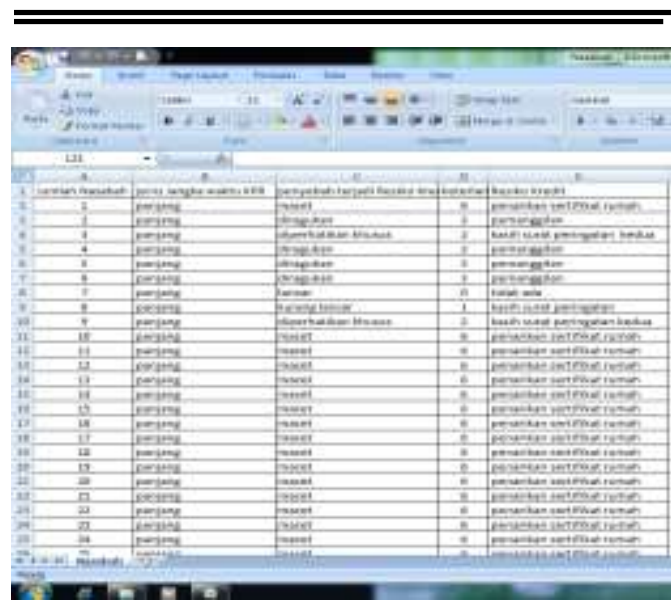

Gambar 2. Contoh Data yang di Inputkan

2. Setelah data diketik semuanya ke dalam Microsoft excel maka data tersebut disimpan dalam format "csv" (Comma Delimited), karena hanya data dalam format "csv" yang dapat dibaca oleh program Dtreg.

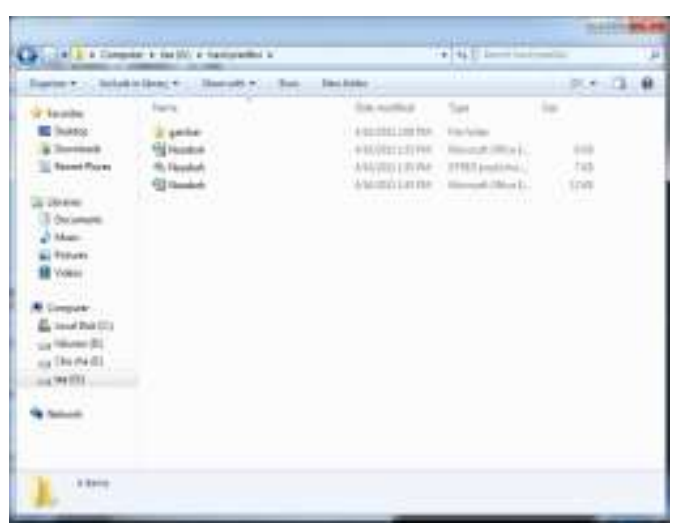

Gambar 3. Penyimpanan Data Dalam Format CSV

3. Kemudian data yang telah disimpan dibuka melalui program Dtreg, dengan memilih tanda pada bagian menu, seperti yang terlihat pada gambar 4.

4. Setelah itu akan muncul gambar seperti gambar 5, kemudian pilih browse dan silahkan masukkan datanya dan pilih next.

5. Kemudian setelah melakukan proses diatas maka akan muncul kolom "time series" seperti gambar 6 lalu next.

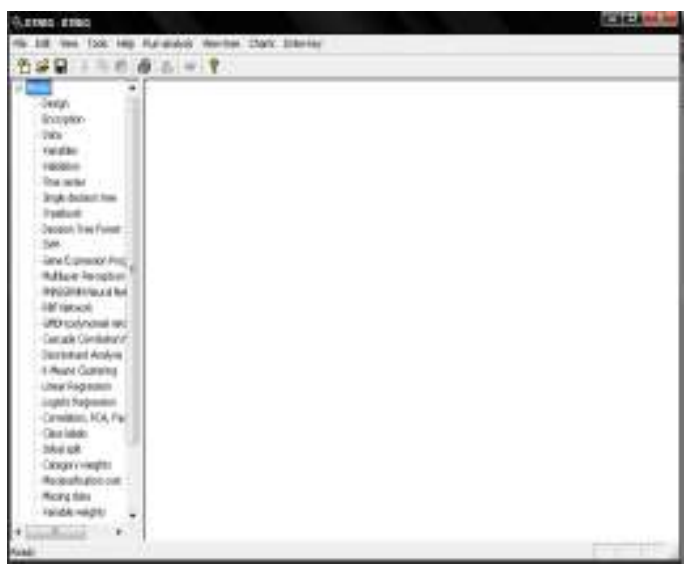

Gambar 4. Tampilan Awal Program DTREG

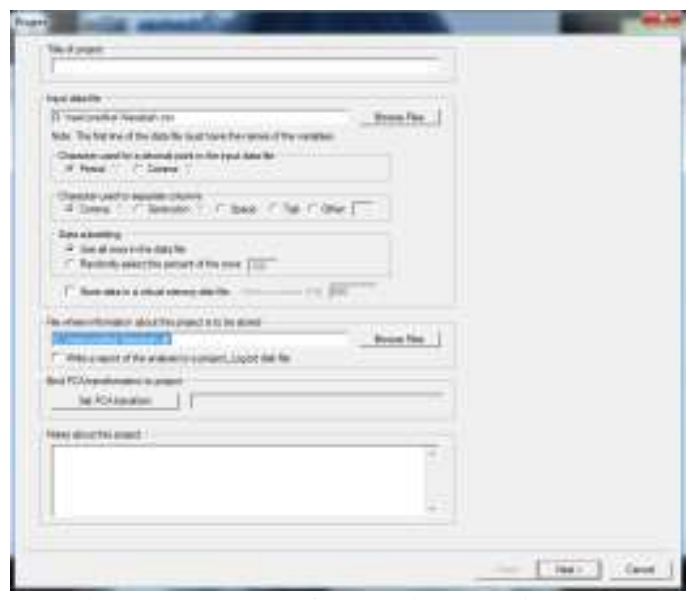

Gambar 5. Proses input data Pada Prgoram DTREG

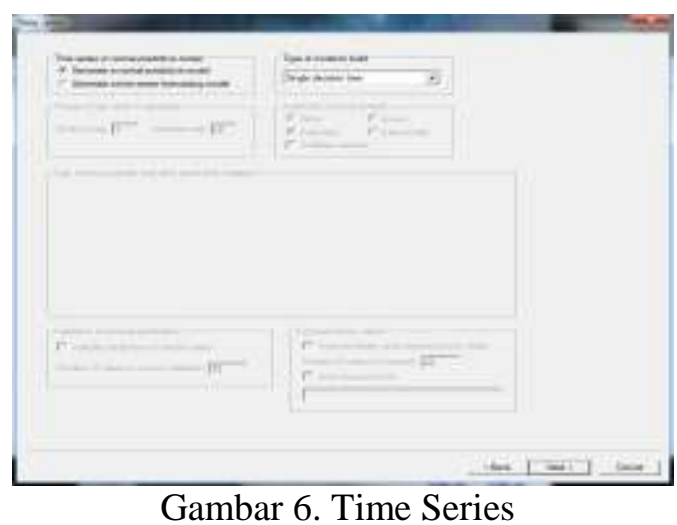

6. Kemudian setelah melakukan proses diatas maka akan muncul kolom "variable" dan dalam penulis ambil berdasarkan penye-bab terjadinya resiko kredit dan keterlambatan per bulan. 
Available online at http://jurnal.stmikroyal.ac.id/index.php/jurteksi

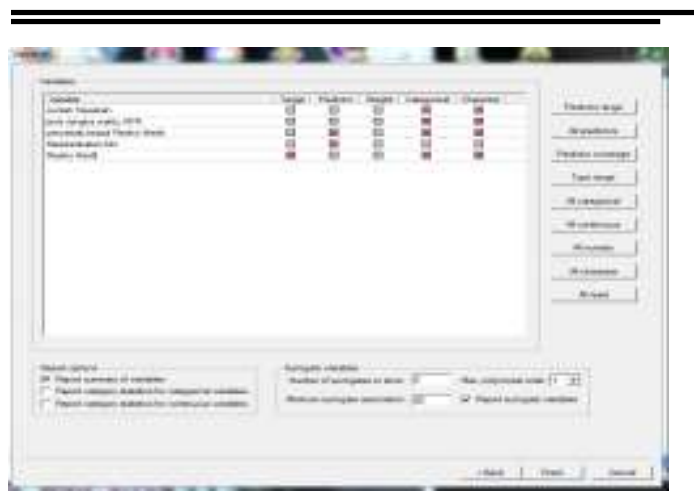

Gambar 7. Variabel Penentuan Resiko

7. Lalu pilih tanda $\Rightarrow \mid$ untuk menjalankan programnya, dan secara otomatis program tersebut akan melakukan analisa terhadap data yang telah kita inputkan. Proses analisa datanya seperti gambar 8 .

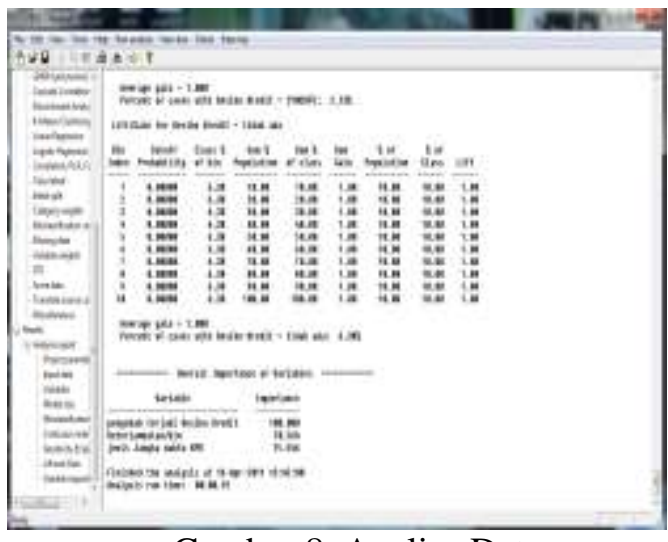

Gambar 8. Analisa Data

8. Setelah melakukan analisa, untuk melihat pohon keputusan (decision tree) maka pilih menu "view-tree", maka akan muncul pohon keputusannya.

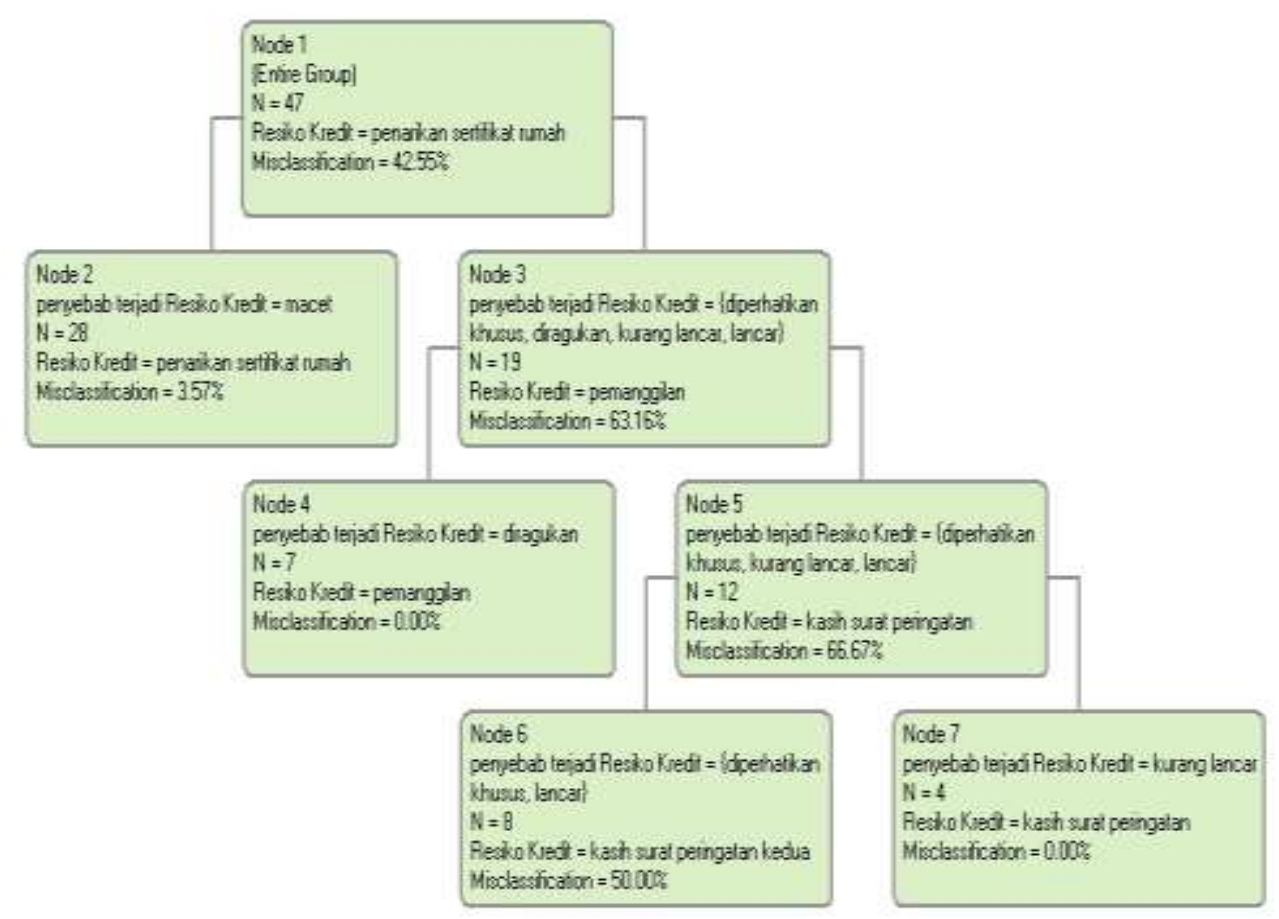

Gambar 9. Output Analisa 
Available online at http://jurnal.stmikroyal.ac.id/index.php/jurteksi

\section{SIMPULAN}

Berdasarkan hasil penelitian dapat dikemukakan beberapa simpulan:

1. Decision tree yang dihasilkan telah mampu menghasilkan knowledge (Resiko Kredit) dengan berdasarkan jumlah nasabah, jenis jangka waktu KPR, penyebab terjadi resiko kredit, keterlambatan per bulan, seperti yang tercatat pada data yang telah diambil.

\section{DAFTAR PUSTAKA}

Moyle, S, A. \& Srinivasan, A. (2001). Classificatory Challenge-Data Mining: A Recipe. Informatica. 25(3): $343-347$

Rauch, J. \& Simunek, M. (2001). Alternative Approach To Mining Association Rules. Proc. IEEE ICDM02 Workshop On Foundation of Data Mining and Knowledge. (eds. Lin, T. Y. and Ohsuga, S.). 157-162.
2. Pemecahan field penyebab terjadinya resiko kredit dan keterlam-batan per bulan menjadi beberapa kelompok kecil membantu user dalam memahami informasi yang dihasilkan dari pohon keputusan yang dihasilkan.

3. Dengan menggunakan software Dtreg juga mampu menentukan resiko kredit pada Bank.
Wettschereel, D. (2002). A KDDSEindependent PMML Visualizer. Proc. ECML/PKDD-2002 Workshop on Integration and Collaboration Aspects of Data Mining, Decission support and Meta-Learning, IDDM-2002. (eds. Bohanec, M., Kavsek, B., Larvac, N. and Mladenic, D.), Helsinki. Finland, 150-155 
Available online at http://jurnal.stmikroyal.ac.id/index.php/jurteksi 
Jurnal Pena Edukasi

Vol. 4 No. 2, Maret 2017
ISSN 2407-0769 e-ISSN 2549-4694 